\title{
A Comparative Analysis of Chinese and British Consumers' Consumption Behaviours and Attitudes Toward Fast-Fashion Brand as Zara and $\mathrm{H} \& \mathrm{M}$
}

\author{
Shan Jiang ${ }^{1}$ \\ ${ }^{1}$ Tongling University, Tongling, Anhui, China \\ Correspondence: Shan Jiang, Tongling University, Tongling, Anhui, China.
}

Received: June 20, 2020

Accepted: July 7, 2020

Online Published: July 11, 2020

doi:10.20849/ajsss.v5i2.773

URL: https://doi.org/10.20849/ajsss.v5i2.773

\begin{abstract}
With emerging of economy and increasing awareness, fast-fashion consumption has been a popular trend around the globe. With features of rapid updating speed, competitive capability and unerring insight, fast-fashion brand consumption had been a regular experience for people in the world. However, owning to different consumption perception and cultural background, attitude towards fast-fashion brands varied from one country to another. Therefore, this research was aimed to conduct a comparative analysis on consumption behavior and attitude about fast-fashion brands between Chinese consumers and British consumers. By means of distributing questionnaires to Chinese consumers and British consumers respectively, this research figured out the similarities and differences in relation to consumption behavior and attitude between Chinese consumers and British consumers. Moreover, major factors were explored to analyze their influence on consumption behavior and attitude of consumers. Finally, with the help of research result and its analysis, effective measures were put forward to help fast-fashion brands to motivate Chinese consumers and British consumers to have fast-fashion brand consumption.
\end{abstract}

Keywords: Chinese consumers, British consumers, consumption behavior, fast-fashion brand, Zara and H\&M

\section{Research Introduction}

\subsection{Research Background}

Owing to the improvement of economy and living standard, fast-fashion brands have appeared and gradually become very popular in people's daily life. However, it is important that different consumers from different countries with their own cultural backgrounds would show different consumption preferences and consumption behaviours (Rageh Ismail \&Spinelli, 2012). Nowadays, China is showing its increasing consumption need for fast-fashion products and turning into one of the largest markets for fast-fashion brands. UK is growing steadily in terms of fast-fashion consumption because of its matured market for fast-fashion products. So it can be useful to conduct a relative analysis about consumers' consumption behaviours of fast-fashion brands as Zara and H\&M in China and British.

Fast fashion brands in China are becoming more and more promising and are expected to grow at an amazing speed. Urbanization process and income level lead to large market share of fast fashion products in China. And consumers from middle class enhance awareness of international brands. Thus great potential of fast fashion brands in Chinese market is displayed to the world owning to economic prosperity. Fast fashion brands such as Zara and H\&M are continued to emerge in downtown areas of major cities (Tokatli, 2008). As a leading brand of fast fashion, Zara has entered into Chinese market since 2006 and efforts have been made to attract Chinese consumers by online channel to strengthen competitiveness according to Lopez \& Fan (2009). Fast fashion brands attract attention of Chinese consumers in just a few years with features of fashion, fresh, relatively inexpensive price and relaxed and open shopping environment. Besides first-tier cities, these fast fashion brands like Zara and H\&M have begun to take up market of second-tier cities and third-tier cities. Rocha, Hammond \& Hawkins (2005) pointed out that as target consumers, large proportion of young people make great contribution to market expansion of fast-fashion brands. Furthermore, huge potential of Chinese retail market is full of motivation for fast fashion brands. In recent years, development of apparel industry in China has slow down, but international fashion brands are still viewed as popular consumption trend and valuable field (Turker \& Altuntas, 2014).

Regarding to the consumers who buy fast-fashion commodities, similar features can be found. On a large scale, 
fast-fashion consumers are apt to buy commodities with their capabilities, while pay less attention to higher quality. It is worth mentioning that young people occupy a large proportion of fast-fashion consumers, and traditional social media measures are extensively taken by young consumers to follow fashion trends closely and even buy the latest fast-fashion commodities (Rageh Ismail \&Spinelli, 2012). At the same time, it is worth mentioning that consumers' enjoyable buying and impulsive consumption of fast-fashion commodities can be regarded as obvious tendencies, which greatly affect their consumption actions.

Studies also analysed the ways that are greatly used by fast-fashion brands, revealing that traditional marketing ways like newspapers and magazines are still used, while many fast-fashion brands are paying great attention to the use of social media tools in marketing and branding activities, including blogs, YouTube, Twitter, Facebook, Instagram, Wechat and so on (Gagrielli, Baghi and Codeluppi, 2013).

With regard to the study of Gabrielli, Baghi and Codeluppi (2013) about the consumption practices of fast fashion products, it can be gained that fast-fashion consumption has slowly become mainly part of people's daily lives for a long time. Rocha, Hammond and Hawkins (2005) studied the similarities and differences among British, Brazilian and Chinese consumers, figuring out that British, Brazilian and Chinese consumers have different command for fashion products, advising that it is basic for fashion brands to be fully noted of consumer indicators in order to draw potential consumers attraction and offering important information for the investigation of consumers' behaviours in fashion consumption.

Regarding to the popularity of the fast-fashion industry, Bhardwaj and Fairhurst (2010) gave an analysis that based on different consumption forms, the consumer market is abrupted and divided into several parts, and fast-fashion is attracting more and more consumers, and is gradually becoming an important industry in the fashion world.

Bruce and Daly (2006) used case studies to further investigate fast fashion's complex nature, figuring out the sections that could influence consumers' purchasing behaviours of fast fashion goods. Sheridan, Moore and Nobbs (2006) made an analysis about the role of category management in fast fashion brands' positioning, figuring out that a category approach is useful to build the orientation of fast-fashion businesses.

Obvious differences existed in the market of fast fashion consumption in China and the UK. Market of fast fashion brands in Britain is regarded as representative one and British consumers have been the target consumers of fast fashion products for a long time. British consumers have a better knowledge and aspiration of fashion and devote more energy to pursue fashionable elements, which makes British market of fast fashion products more mature than that of Chinese (Bakewell et al, 2006). It is well known to all that a great number of fast fashion brands such as Burberry derive from native British, which leads the UK to get excellent reputation of fashion. Zara, H\&M and other high street brands are widely acknowledged as leading fashion brands in the UK favoured by female consumers especially. The research suggests that speed and amount of purchasing clothing in the UK is superior to China. However, it should be noted that consumption of fast fashion in Britain is not always optimistic. British consumers may keep conservative attitude under condition of weakening economic development, which will be an awesome challenge for growth of fast fashion industry.

\subsection{Research Significance}

This research takes full advantage of knowledge gained in relation to fashion management, and catches the opportunity of using theoretical knowledge with practice. When making this research, it can offer some interesting thoughts regarding deep understanding of fast-fashion consumers, especially the similarities and differences about Chinese and British consumers behaviours over fast-fashion consumption. At the same time, the research feedback can give some thoughtful ideas for fast-fashion brands with regard to make efficient marketing and branding strategies to draw British and Chinese consumers' attraction about fast-fashion consumption.

\subsection{Research Structure}

This research will be consisted of five chapters with the main focus to explore the differences between Chinese and British consumers' custom over fast fashion brands such as Zara and H\&M. Chapter 1 will be an introduction chapter, illustrating the research aim and objectives, research questions, research significance and research structure. Chapter 2 will pay attention to learn from previous studies in this field in an attempt to gain some valuable insights for the current research over the differences of consumption behaviours and attitudes between Chinese consumers and British consumers. Chapter 3 will analyse the research methodologies taken in this research, mainly concerning on the discussion of aspects such as research design, research philosophy, research methods, data collection, ethical considerations and potential limitations. Chapter 4 will comprehensively evaluate the research results gained from this research with the focus on the analysis of primary data collected. Chapter 5 will serve as the conclusions section together with the recommendations. 


\subsection{Research Aim}

The aim of this research is to have a relative analysis of Chinese and British consumers' consumption behaviours towards fast-fashion goods in order to get some valuable thoughts about fast-fashion brands, and doing efficient marketing and branding activities. Here are research aims.

To explore (18-59 years old) Chinese consumers' consumption behaviours and fast-fashion brands like Zara and $\mathrm{H} \& \mathrm{M}$.

To analyze (18-59 years old) British consumers' consumption behaviours and customs about fast-fashion brands such as Zara and H\&M.

To figure out the similarities and differences about Chinese and British consumers over fast-fashion consumption.

To give advice regarding the specific ways by fast-fashion brands such as Zara and H\&M to draw Chinese and British consumers' attraction.

\subsection{Research Questions}

In accordance with the research objectives, this research will focus on exploring the answers for the following questions.

What are the main similarities among Chinese and British consumers in terms of their consumption behaviours of fast-fashion goods?

What are the main differences between Chinese and British consumers in terms of their consumption behaviours of fast-fashion goods?

What marketing measures can be effective to motivate the fast-fashion consumption of Chinese consumers and British consumers respectively?

\section{Literature Review}

\subsection{Introduction}

Fast fashion can be viewed as a contemporary term that is widely adopted to demonstrate fashion designs on the catwalk with the aim to effectively grasp fast-changing fashion trends (Turker \& Altuntas, 2014). Many studies have been used to discuss consumer preferences and behaviours, which can be regarded as useful resources in order to achieve an excellent study towards this research. This chapter is mainly focused to have a deep understanding on literature review related to consumption behaviours and attitudes toward fast fashion products such as Zara and H\&M among consumers in China and British. Specifically speaking, this section will explore market situation of fast fashion brands in terms of China and the UK. Through research, major similarities and differences with regard to consumption behaviours and attitudes of fast fashion products from Chinese and British consumers will be presented. Meanwhile, influential factors which lead to differences in consumption perception and behaviour of fast fashion products will be dug out to give convincing and reliable illustration. Finally, this research will put forward effective measures for fashion management to attract more consumers to fast fashion consumption.

\subsection{Similarities and Differences Regarding Consumption Behaviour of Fast-Fashion Goods Between Chinese and British Consumers}

This section will analyse similarities and differences between Chinese consumers and British consumers to have a better understanding of their purchasing behaviour regarding fast fashion consumption according to research of Bruce \& Daly (2006). When it comes to similarities, financial capacity plays a critical role for Chinese consumers and British consumers to purchase favourite fast fashion brands. Income level of consumers in China and the UK has direct influence on consumption ability. Consumers with higher status and financial strength are capable of purchasing prevalent fast fashion products to make themselves become more distinctive and international. Financial capacity creates decisive impact on consumption level and decision making. Gabrielli, Baghi and Codeluppi (2013) expressed that the demand for fast fashion brands is one of the similarities between consumers' behaviours in China and the UK, which is taken as a valuable $g$ of consumption behaviours. The consumers in two countries need purchase fast fashion brands to cater for higher hierarchy need to achieve refinement of self-image and achievement of self-value (Choi et al, 2010).

Knight and Young Kim (2007) indicated that brand perception of Chinese consumers and British consumers is similar to each other in facilitating consumption of fast fashion brands. Consumers in China and the UK have conception in common that fast fashion brands are featured with first-class design, second-class quality and 
third-class price. Fast fashion brands collect valuable information about fashion from various channels and then launch new products within 12 days, which satisfies the need of efficiency of consumers. Well-known brands stimulate the desire of consumers for purchasing fashion products. Both Chinese consumers and British consumers prefer to follow up fashion trend. As for fast fashion brands, the amount of production of each clothes is very small and no repeated style is guaranteed, which is an effective channel to meet the need of uniqueness in consumers' mind.

However, different countries display different consumption features of fast fashion brands owning to different social and cultural background (Belk et al, 2005). The research has shown that Chinese consumers and British consumers have different consumption behaviours and attitudes in terms of fast fashion brands. Firstly, as for majority of Chinese consumers, they aim at showing off their wealth, status and power to others by fast fashion consumption so as to obtain individual honour and dignity. Consumption of fast fashion brands is a visible way for Chinese consumers to be distinguished from others and reflect their unique taste and personality. Carrying international and popular fast fashion brands in public can get excellent acknowledgement and admiration from other people and win respect. Moreover, Goldsmith, Flynn \& Kim (2010) gave a view that Chinese consumers focus more attention on the brands represented token of identity. It is because that individual social status is reflected by economic strength to a great extent, which makes wealth displaying become social symbol. Snob motivation suggests that main reason for Chinese consumers to buy fast fashion products to be more superior to the public. They can purchase the brands in the first time when new products entering into market. Some other Chinese consumers who are sensitive about status will not purchase the fast fashion brands consumed by the public.

From the perspective of traditional culture, face is a critical factor for Chinese consumers to be large consumption country of fast fashion brands all over the world. However, British consumers prefer inner information of fast fashion brands. Chinese consumers are inclined to lay an emphasis on quality and reliability of fashion brands, which reflects values of British consumers who consider fast fashion consumption as a regular behaviour instead of showing off. Secondly, fast fashion brands in China are at the stage of great growth. More and more Chinese consumers are enthusiastic about fast fashion brands. Young people in China make great contribution to fashion industry in particular. Their ability of consumption on fast fashion brands is impressive in spite of slowdown of economic growth. Chinese young consumers utilize technological innovation like online shopping to make purchasing. In the UK, middle-age consumers with powerful financial strength take up a large proportion and they prefer the consumption in physical stores. There is no financial pressure for them to purchase fast fashion brands. Chinese consumers enjoys hedonic consumption through purchasing fast fashion brands while British consumers propose individualism which views fast fashion consumption is based on economic capacity.

\subsection{Factors Influence Consumers' Consumption Behaviours and Attitudes of Fast-Fashion Goods}

Without a doubt, consumption behaviours and attitudes related to fast fashion consumption of Chinese consumers and British consumers are driven by certain factors from perspective of Zhang \& Kim (2013). Therefore, this section will focus on influencing factors and explore their importance to consumers. There are four chief factors that are of great value in influencing consumption behaviours and attitudes of Chinese consumers and British consumers when purchasing fast fashion products.

Social factors. Consumers from Chinese and British will be impacted by the groups which they belong to in the whole society. Goldsmith \& Clark (2008) expressed that value and consumption behaviours of the same social groups will be a popular consumption trend of fast fashion brands. Fashion brands are necessary to well understand specific features and meet consumers' expectation about fast fashion products to obtain social benefit. Perception and consumption habit of family members can have a direct effect on consumption behaviour and purchasing pattern of other members correlated to brands and functions of fast fashion products. As fundamental component of society, family is an indispensable driving force for other members to be loyal consumers when purchasing fast fashion products. More importantly, social status and identity of individual consumers play a significant role in affecting fast fashion consumption of Chinese consumers and British consumers. Consumers prefer to choose products with superior quality to interpret their wealth and taste and win respect from others.

Personal factors. Barnes \& Lea-Greenwood (2006) pointed out that the ability of buying international fast fashion brands is up to purchasing power of Chinese consumers and British consumers. What the consumers purchase and the decisions they make are based on their income level, which creates direct influence on their choices on brands and consumption level. Both Chinese consumers and British consumers have high expectation on their individual personality and self-concept, which is dedicated to shaping outstanding individual image and be different from others. Positioning self-image as positive element has close 
relationship with purchasing behaviours and attitudes. Majority of consumers would like to achieve the image they want to be in their mind through consumption of fast fashion products. Meanwhile, different age and gender of Chinese consumers and British consumers will treat fast fashion brands in different insight. Therefore, fashion brands should make full investigation and tailor their need.

Cultural factors. Cultural factors include belief, attitude and customs, which show certain characteristics of a society. It is acknowledged that culture has profound and extensive influence on consumption behaviours and attitudes of fast fashion brands for Chinese consumers and British consumers. The culture the consumers touch has decisive effect on consumers' lifestyle and even their purchasing decision. Currently, sub-culture is getting more and more attention, which is viewed as an indicator to be utilized to cater for need of different market and set up marketing strategies learned from the study of Gabriell, Baghi and Codeluppi (2013). For instance, dressing style and habit in a specific area will produce limitation on sales of fast fashion brands with innovative designing. It is required that fast fashion brands need learn about local cultural features when entering into new marketplace in order to gain satisfying sales achievements.

Psychological factors. According to Hierarchy of Needs of Maslow, consumers have different needs at different stages, which forms variable motivations (Poston, 2009. Motivation of purchasing fast fashion brands is a channel of expressing self-need of consumers in Chinese and British. Motivation to pursuit fashion products displaying taste forces consumers to make consumption decision with positive attitude. Cognition of consumers on fast fashion brands varies relying on consumers' thinking. According to cognition theory, consumers will only focus on valuable information in light of practical need when selecting fashion brands in department store. With aim of buying superior product, consumers will ask for information from those people who have used the products to shun unnecessary trouble.

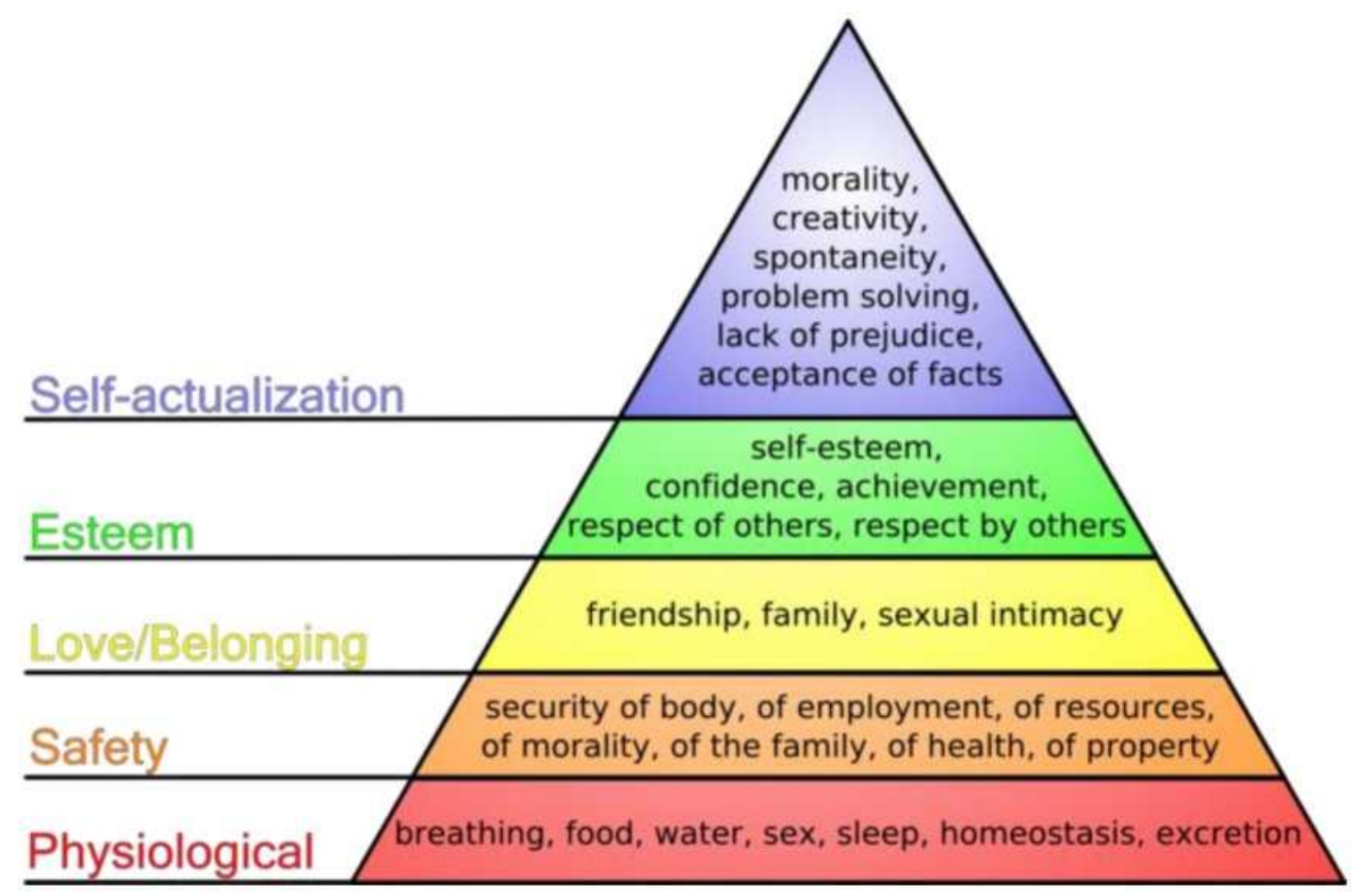

\subsection{Strategic Measures to Stimulate Fast Fashion Consumption of Chinese Consumers and British Consumers}

Analysis of market situation and factors that influence consumption behaviours and attitudes are beneficial approaches for international fast fashion brands to set up specific measures to motivate Chinese consumers and British consumers.

Fuchs \& Diamantopoulos (2010) interpreted that fast fashion brands should have accurate brand positioning and shape unique characteristics distinguished from others. In order to capture design concept and the latest fashion 
trend, young designers of fashion brands like Zara and H\&M are busy in watching fashion show in Milan, Paris and other famous places and further promote fashion products with excellent emulation effect at amazing speed. Updating efficiency of products in speciality stores around the globe leads the consumers to increase loyalty. What's more, design teams should in time strengthen communication with the management of each store to well understand sales volume and consumer response so as to adjust to design direction in a flexible way and cater for variable taste of consumers. Meanwhile, the management of each store can be active to give effective feedback to the designers for their reference, which facilitates them to analyse consumer's preference and future design concept to maximize sales and reduce inventory products.

Building effective supply chain system is a valuable measure for fast fashion brands to stimulate consumers in Chinese and Britain from standpoints of Tyler, Heeley and Bhamra (2006). Efficient supply chain system shortens leading time of fashion products, which means high efficiency from initial designing to eventual sales. Fast fashion brands can depend on rapid response, efficient integration, full control and process compression to decline leading time, which has advantage in grasping fashion trend and minimize prediction risk. Making leading time under control is helpful for fast fashion brands to provide valuable information for end users through supply chain system. For ensuring transportation, fast fashion brands have self-constructed logistics adopted by Zara and the third party transportation utilized by H\&M. With clear objective, supply chain system is critical for fast fashion brands to improve efficiency of production and commodity circulation, which provides Chinese consumers and British consumers for satisfying fashion products and service under complex competitive environment. Under guideline of the supply chain system with principle of achieving higher satisfaction and lower cost, it is essential for fast fashion brands to design reasonably under real situation.

Following fashion trend learned from well-known fashion show may lead fast fashion brands to face censure and trouble, which cannot be affordable to them. Therefore, it is necessary for fast fashion brands to reach cooperative relationship with luxury brands at proper time to reduce risks and improve management mode (Turker \& Altuntas, 2014). Meanwhile, luxury brands can benefit from this cooperation in improving sales condition, expanding marketing channel and cultivating consumer groups. H\&M together with Lanvin initiates new development pattern of fast fashion brands and luxury brands. Cooperating with luxury brands is regarded as win-win strategy for fast fashion brands and luxury brands to seek new breakthrough point.

Fast fashion brands should make use of differentiated market positioning strategy and category management to make segmentation of market, which chiefly relies on closer relationship with consumers' demand and complete integration of regional resources (Sheridan et al, 2006). Products with low price but high quality should be launched by fast fashion to cater for psychological need of following popularity.

According to the research of Choi, Liu, Mak and To (2010), it can be gained that brand loyalty, involvement, perceived quality, self-image, brand concept correlation and product character similarities can be regarded as important factors that might influence consumers' buying behaviours about brand extensions. Joo Park, Young Kim and Cardona Forney (2006) explored the effects of consumers' fashion involvement and positive attitude towards consumers' enjoyable consumption tendencies as well as fashion-oriented impulsive purchase, figuring out that fashion involvement and positive emotion can greatly positive impacts on encouraging consumers' fashion- oriented impulsive buying behaviours. When investigating fast-fashion brands' marketing, it can be useful for fast fashion brands to draw attention further develop consumers' fashion involvement and take measures to encourage consumers' fashion- oriented impulsive purchasing.

Rageh Ismail and Spinelli (2012) mainly focused on the analysis of fashion brands over young consumers with the results showing that brand image can be regarded as an important section of brand love which affects word-of-mouth. More specificly, Rageh Ismail and Spinelli (p.394) advised that brand image and brand personality should be regarded as efficient strategies for fashion brands to consumers' emotional relationships with fashion brands and then achieve consumer loyalty.

Tokatli (2008) carried out the case study of Zara, pointing out that as a pioneer of fast fashion principles; Zara has grown into a well-accepted example in fast-fashion retailing. Barnes and Lea-Greenwood (2010) analysed that the coverage of fashion in media contributed to consumers' improving fashion awareness, which should be considered when enhancing consumers' brand awareness. Therefore, for fast-fashion brands, the importance of media should not be ignored when it comes to influence consumers' high street fashion's consumption behaviours.

\subsection{Summary}

Through learning from previous researches on the exploration of consumers' fastfashion consumption, this research has obtained some relevant insights concerning to making a comparative analysis of the similarities and differences in fast-fashion consumption between Chinese and British consumers. However, it should be admitted 
that previous studies might not focus much on this field, making it quite challenging to find out reliable and convincing research outcomes in this research. Therefore, more efforts should be made to put forward a relatively well-developed research design, to ensure the data collection process to be carried out in a smooth way, to analyse the collected data reasonably and eventually come out with satisfactory research outcomes.

It is no doubt that research methodology is considered as an effective way to dig out the truth of a given theme on a specific perspective (Peffers et al, 2007).

\section{Discussion of Methodologies}

\subsection{Chapter Overview}

This chapter will discuss the research methodology utilized by the researchers in carrying out the comparative analysis of Chinese and British consumers' consumption behaviours and attitudes toward fast -fashion brands like Zara and H\&M. Significance of research methodology will be presented to illustrate the necessity of implementing it in order to get reliable and insightful research findings. Furthermore, research methodology will include research design and procedure, questionnaire design and analysis, data collection and sample description to make the research more rational and logical. Some factors which can lead to variables of collected data will be explored. Finally, limitations will be put forward to have a reflection for previous studies and further improvement in the future research.

\subsection{Significance of Research Methodology}

Research methodology means a series of methods applied by the researchers to promote a particular research under premise of rational research hypothesis to dig out the trustworthy evidence for the research topic. As a comprehensive approach, research methodology provides a philosophical framework for approaching research. It is research methodology in this dissertation that takes effect in making a comparison regarding market situation between Chinese market and British market together with differences and similarities related consumption behaviour and attitude on fast-fashion brands.

In the process of facilitating the final findings, research methodology is employed with different standard for providing solutions to research questions. For purpose of exploring the factors which have influence on consumption behaviours and attitude towards fast-fashion brands between Chinese consumers and British consumers, factors in terms of social, personal, psychological and cultural are analysed to search for answers. By taking advantage of research methodology, the researchers can stimulate the relative industries to figure out more innovative ideas through current and previous collected data and information for their reference. Unanswered questions or the fields which have not exploited can be gained brand-new knowledge with systemic and appropriate method by overcoming research problems (Burck, 2005).

\subsection{Design and Procedures}

Research design means a detailed outline for conducting research. As an overall strategy, research design plays a critical role in coordinating different research sections (Creswell, 2013). Therefore, a well-developed research design is essential for achieving ideal research results. Effect of research design is to make sure gathered evidence can provide effective solutions for researchers to research questions. For this research, it will utilize both quantitative and qualitative research as research methods. Questionnaires will be distributed randomly to the people outside the shopping mall in China and the UK respectively, which is aimed to achieve following understandable items: (a)consumption preference, (b) consumption behaviour and attitude, (c) strategic measures which can stimulate fast-fashion brands.

Understanding on consumption preference can be realized by the theory of the consumers (White \& Dahl, 2006). According to their willingness, consumers make decisions and give priorities regarding the fast-fashion brands which are preferred by them. Based on consumption economics and behaviours science, consumption behaviour is paid attention by researchers in light of external environment such as social factors. Experience and perception on fast-fashion brands have influence on consumption behaviours. Analysis about consumption attitude towards fast-fashion brands from aspects of emotion, cognition and behaviour will be carried out. Owning to consumers' inclination, consumption attitude has influence on the choices of fastfashion brands.

\subsection{Questionnaire Design}

In order to gather valuable and helpful data, 200 well-structured questionnaires were distributed at random to the people outside fast-fashion brand stores in China and the U.K respectively, which were made up of three main sections. Questions in the first section were demographic information, which refers to gender, age, occupation, income level regarding to the respondents. The second section was aimed to investigate influential factors on the 
respondents when they considering fast-fashion brands, which includes price, after-sales service level, promotional channels of fastfashion products. The final section was correlated to the psychological perspectives which have influence on purchasing intention, which involves brand perception and awareness, purchasing motivation.

It can be learned from questionnaire design that this research is analysed from three levels. At the very beginning, this research leads people to have a general knowledge of consumption behaviour and attitude towards fast-fashion brands. Then, this research focused on comparative analysis on consumption behaviour and attitude on fastfashion brands between Chinese consumers and British consumers, which has intention to make comparison of fast-fashion brands consumption under emerging economy and matured market. At last, this research laid emphasis on two specific fast-fashion brands named Zara and H\&M that are well-known fashion brands to consumers of the two countries. Major similarities and differences concerning consumption behaviour and attitude on fast-fashion brands between Chinese consumers and British consumers can be understood through detailed levels of analysis.

\subsection{Data Collection and Sampling}

Based on this research, sampling is necessary for the researchers to make analysis related to the people who are involved in answering research questions to meet the research aims and objectives. As for this research, the target audiences were Chinese and British who have ability and aspiration to experience fast-fashion brands consumption. In the distributed questionnaire, 200 people in total who appeared around department stores of fast-fashion brands were selected as the target respondents of this research, including 100 Chinese consumers and 100 British consumers. And a series of questions were listed to seek the potential answers to the research questions. This research made great effort to make sure the respondents were randomly selected in China and in Britain so as to enable the research results to represent the perspectives of general Chinese and British consumers of fast-fashion brands. Although a relatively small percentage of people were invited to participate in the process of this research, the sampling results were still considered as quite useful reference for this research to achieve convincing research outcomes. Under requirement of randomness, probability sampling was selected by the researcher to understand consumers at different age and consumption level.

With regard to the sample profile, this research distributed the questionnaires to both male respondents and female respondents in the research process to ensure that both women and men were participated in this research to share their viewpoints over fastfashion consumption. It is well known that gender has close relations with fast-fashion products, and especially the female consumers show more enthusiasm and aspiration compared with male consumers (Howarton \& Lee, 2010). Age of the respondents was considered as a powerful element related to fast-fashion brands consumption, which indicated that young consumers have strong tendency owning to fast-fashion brands cater for their need from different angles. Furthermore, income level of consumers was shown positive correlation to consumption behaviour and attitude on fast-fashion brands. Consumers with high income level are more inclined to purchase fast-fashion brands. Vice versa, consumer groups with low income level make less contribution to fast-fashion products. Moreover, psychological factors of consumers in China and Britain were associated with consumption behaviour and attitude about fast fashion brands. For example, in order to have face and show social status, Chinese consumers displayed great concentration on fast-fashion brands via various channels. Meanwhile, they spent a large proportion of annual salary on fast-fashion products, while British consumers might be inclined to show their unique taste and pursuit for superior quality by means of fast-fashion brand consumption.

\subsection{Variables of Data}

Consumption behaviour and attitude on fast-fashion brands can be affected by certain factors. Pursuit and enthusiasm on fast fashion brands consumption are driven by some factors, including brand perception, psychological demand such as showing social status and personal taste and relative aspects. However, of particular note, consumption behaviour and attitude on fast fashion products are not always the same at every stage. There are variables generated by different reasons, which needs the researchers to pay attention and search for corresponding measures to stimulate fastfashion brands consumption.

As the fundamental unit of market, characteristics the consumers have great influence on growth and consumption of fast-fashion brands. Especially, income level of the consumers is strongly associated with increasing sales volume and improving brand values of fast-fashion brands (Hustvedt \& Dickson, 2009). With higher income level, consumers might be more loyal to a certain fast-fashion brands. Moreover, with higher income level, the consumers have powerful ability to undertake risks and have a preference for fast-fashion brands. However, income level of the consumers will be vary owning to job performance of consumers, industry development and 
payment strategies of human resources, which further forms uncertain influential factors to promote fast-fashion brands.

In terms of the brands themselves, only rapid and consistent innovation can win loyalty and aspiration from consumers. As for the young consumers who have preference on fast-fashion brands, they are attracted by rapid reaction of fast-fashion brands. This requires fast-fashion brands to follow up fashionable elements and ensure updating at an amazing speed (Johar, Sengupta \& Aaker, 2005). Furthermore, the consumers would like to display their personality according to fast-fashion brands, which requires brands to combine fashion trends with brand style to cater for the need of consumers. Therefore, speed of reaction and updating will be variables for influencing fast-fashion brands consumption.

Methods of brand promotion can be viewed as variable that has impact on fast-fashion brands. It is well acknowledged that fast-fashion brands should make full use of social media to promote products (Goh et al, 2013). For instance, H\&M can update timely fashionable news and product information through its own web page on well-known Facebook. In contrary, with less advertisement promotion, Zara makes use of physical department stores to enable consumers to experience professional and superior service. Therefore, promotion strategies will influence consumers' perception on fast-fashion brands and purchasing decision. What's more, access to internet marketing can be variable of fast-fashion brand consumption of consumers.

\subsection{Limitation}

This research involves various perspectives in order to make the comparative analysis about consumption behaviour and attitude on fast-fashion brands between Chinese consumers and Britain consumers. Many endeavour has been made by the researchers. However, there are still some limitations existing in the holistic research process. More questionnaires would have been distributed to the respondents with the aim of gathering credible data and information. If time allows, more variables that can have influence consumption of fast-fashion brands will be dug out to meet the research aims and objectives. Besides, other potential options of data collection could have been used in this research in order to acquire more useful and supportive data. For example, interview, which is a popular way to be adopted in academic studies, can be used in this research to obtain first-hand information concerning this research.

\section{Discussion of Research Results}

\subsection{Introduction}

This research focused on making a comparison between Chinese consumers and British consumers' fast-fashion consumption behaviours, the questionnaire feedbacks received from Chinese and British consumers respectively served as valuable data to help this research to develop effective research outcomes. When analyzing the data collected, this research tended to compare Chinese consumers and British consumers' answers to this each question so as to find out the similarities and differences between the two types of consumers toward fast-fashion consumption.

\subsection{Overview of Respondents}

In this research, 100 questionnaires were sent to Chinese consumers and British consumers respective and the respondent rates of Chinese and British respondents were $93 \%$ and $97 \%$, which could be regarded as effective data for this research.

Table 1. Response rate

\begin{tabular}{ll}
\hline & Response Rate \\
\hline Chinese Consumers & $93 \%$ \\
\hline British Consumers & $97 \%$ \\
\hline
\end{tabular}

In this research, $62 \%$ out of the 93 Chinese respondents were female, while the male Chinese consumers accounted for $38 \%$. For the British consumers, female consumers accounted for $58 \%$ of the total British consumers and the male consumers took up $42 \%$. These figures showed that this research had reasonable combination of both female and male respondents to ensure the results gained from this research can be useful to represent the perspectives of Chinese consumers and British consumers of fast-fashion goods. 


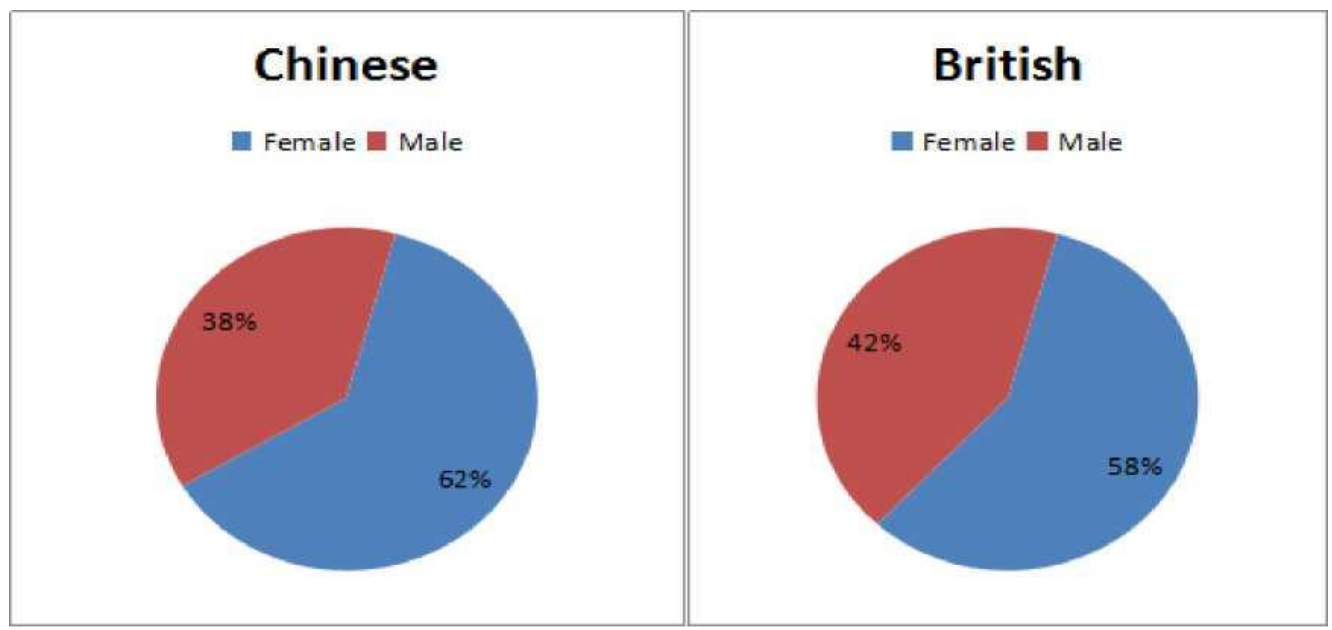

Graph 1. Gender proportion of Chinese and British Respondents

When considering the age of the respondents, it can be seen from the graph below that the Chinese consumers who participated in this research concentrated on the age between 20 and 29 as well as between 30 and 39, while the British consumers participated in this research showed similar age groups, even though the proportion of the two age groups between Chinese consumers and British consumers were not the same. This result served as a beneficial condition to enable this research to focus on the exploration of the consumption behaviours and preferences of Chinese and British consumers aged between 20 and 39.

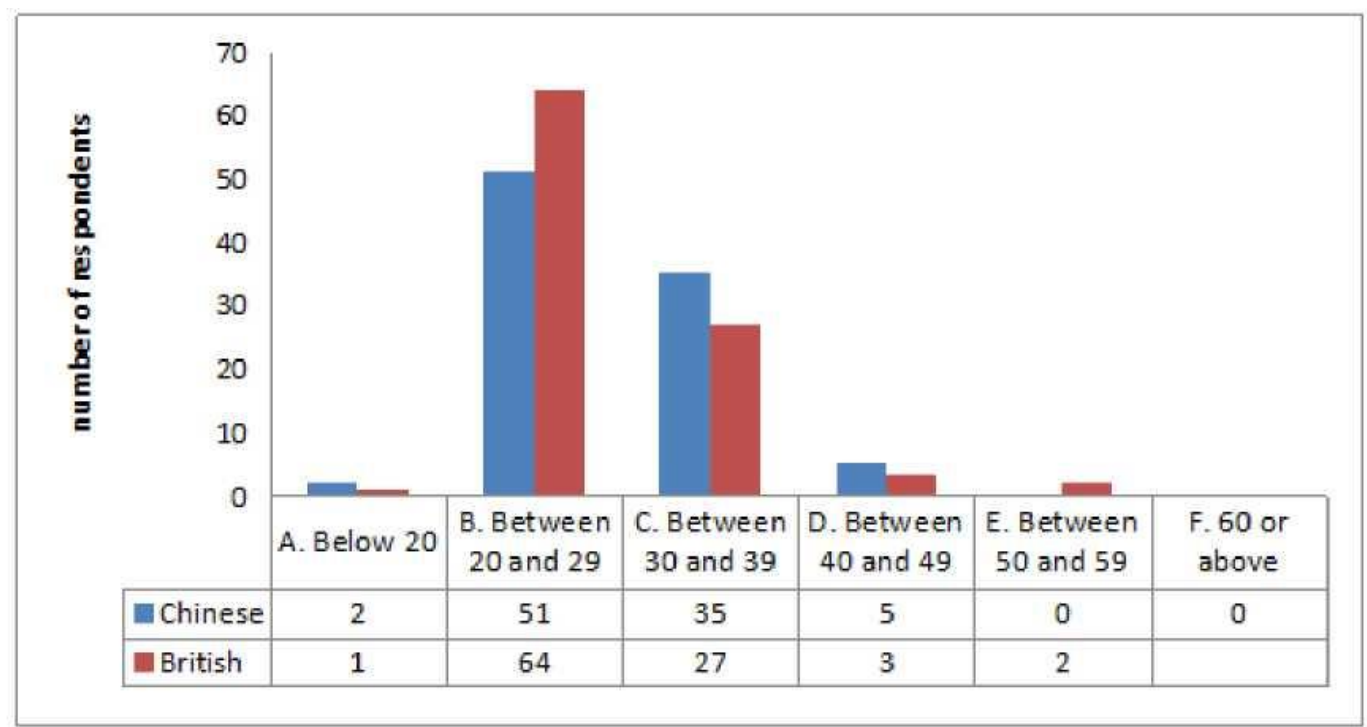

Graph 2. Age of Chinese and British respondents

This research also evaluated the salary level of the respondents and the research outcomes collected showed that the majority of Chinese respondents and British respondents in this research concentrated on consumers with the annual salary between $£ 10,000$ and $£ 40,000$. It is also believed that consumers at this range of annual income might be the largest potential consumers of fast-fashion brands, making the research results more convincing. 


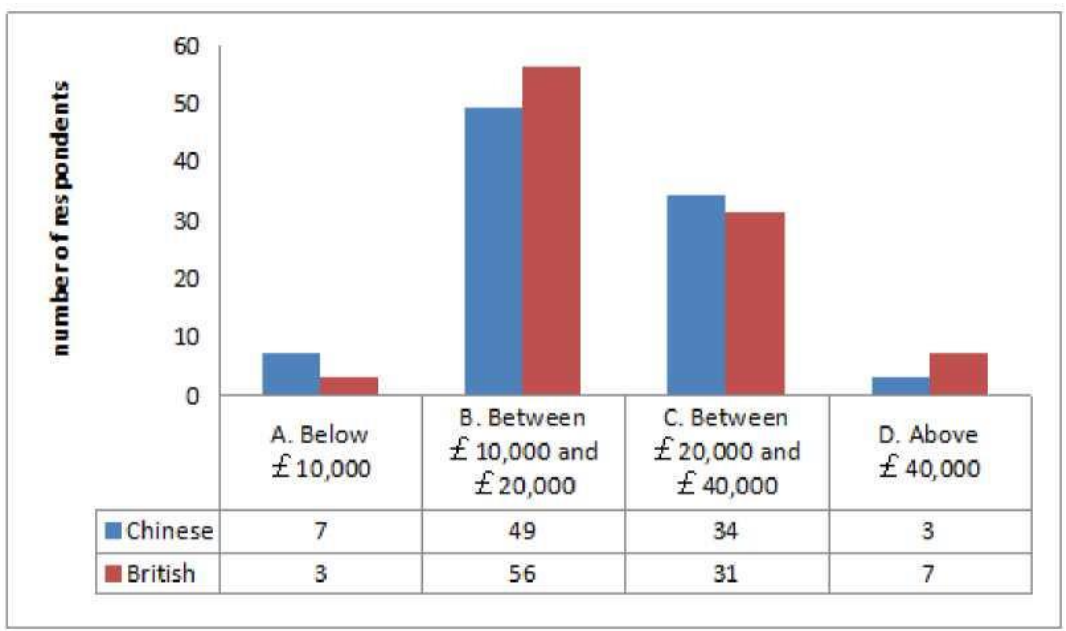

Graph 3. Annual income level of Chinese and British consumers

When making a comparison between Chinese consumers and British consumers in terms of their consumption frequencies of fast-fashion consumption, the results gained can be reflected from the graphs below. It can be seen from below graph that frequencies between 2 and 5 times per month accounted for the largest proportion in China and British. In China, the second largest percentage of fast-fashion consumption frequency was between 6 and 10 times per month, while percentage of between 6 and 10 times per month among British consumers was $20 \%$. What's more, fast-fashion consumption frequency less than 2 times per month formulated striking contrast between Chinese consumers and British consumers, which were 5\% in China and as high as 34\% in British. Through carrying out a comparative analysis of Chinese and British consumers' frequencies of fast-fashion consumption, this graph can provide a valuable reference for fast-fashion brands to have a better understanding of different consumers and take corresponding measures to motivate consumers' consumption behaviours.

British consumers

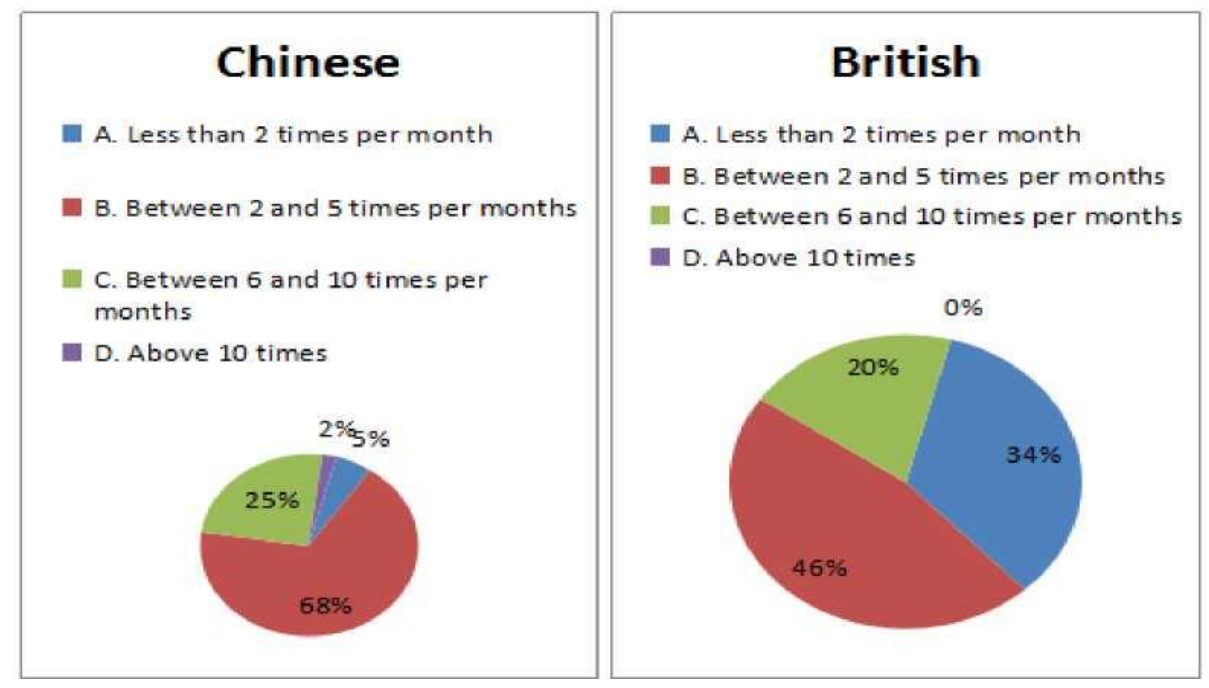

Graph 4. Frequencies of fast-fashion consumption between Chinese consumers and British consumers 
For Chinese consumers who have engaging in fast-fashion consumption, the proportion of Chinese respondents with the consumption experience between 1 and 3 years was as high as 55\%. While the largest percentage was 39\% among British consumers with the consumption experience of British consumers between 4 and 5 years. The proportion of Chinese consumers with the consumption experience of less than one year was $33 \%$. However, only $6 \%$ of British respondents have fast-fashion consumption experience of less than one year. Meanwhile, sharp contrast regarding consumption experience above 5 years existed in the fast-fashion consumption between Chinese consumers and British consumers, which were $4 \%$ and $28 \%$ respectively. This graph suggested that consumption experience of Chinese consumers was not adequate as an emerging market of fast-fashion brands, while it had been regarded as regular consumption behaviours of British consumers as a matured market of fast-fashion brands.
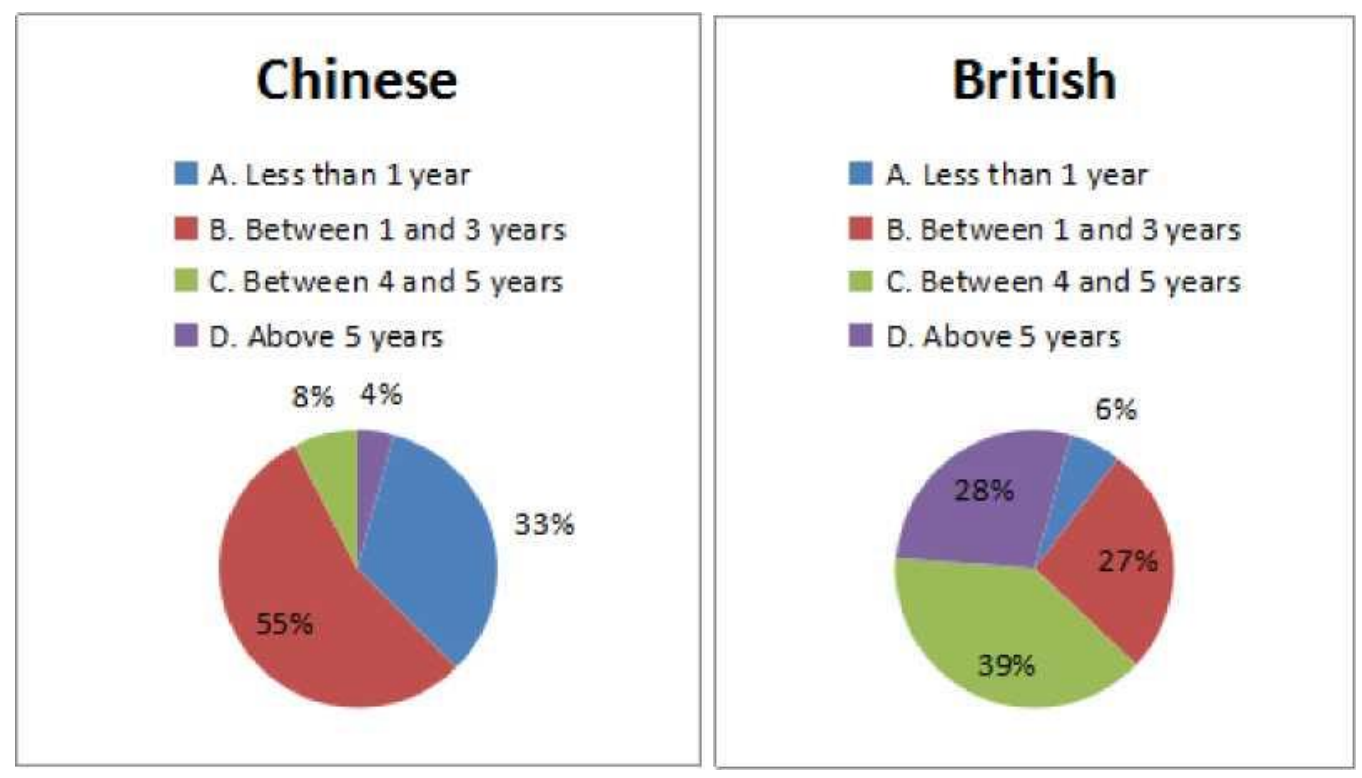

Graph 5. Consumers consumption experience of fast-fashion brands

As for Chinese consumers and British consumers, they have their own reasons when choosing fast-fashion brands consumption. For Chinese consumers, fashion design and attractive price were main driving forces to consume fast-fashion brands. While it was personal style and superior quality of fast-fashion brands that stimulated British consumers to be enthusiasm about fast-fashion consumption. Moreover, some other factors also indicated in this research the reasons that motivated Chinese consumers and British consumers to purchase fast-fashion goods, which involved convenience and following the fashion trend. And the percentage of each reason is quite different between two countries. This graph can be an effective channel for fast-fashion brands to set up strategic marketing approaches according to different major reasons to attract potential China consumers and British consumers respectively. 


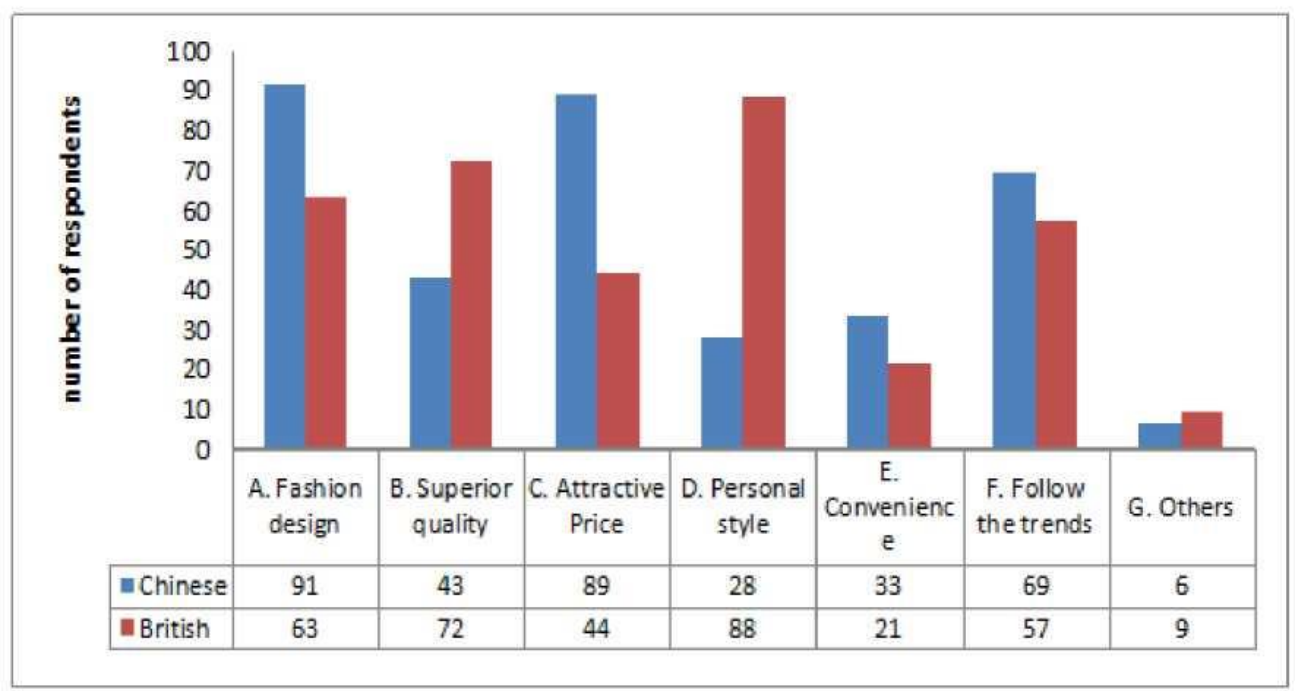

Graph 6. Reasons for fast-fashion consumption between Chinese and British consumers

With regard to the question that what elements Chinese consumers and British consumers will consider while making fast-fashion brand consumption, it can gain some insights from the following graph. The most popular element considered by the majority of Chinese respondents in this research was sales promotion, which might inspire fast-fashion brands to pay more attention to this aspect and apply appropriate methods of sales promotion to stimulate consumption aspiration of Chinese consumers. Meanwhile, constant sales promotional plans can help fast-fashion brands to win fixed Chinese consumer groups. The second popular element selected by Chinese consumers was celebrity effects, which was an effective implication for fast-fashion brands to make good use of popular celebrity as brand endorsers to attract Chinese consumers, gain their trust and loyalty so as to and enhance the entire performance of fast-fashion brands. While British consumers viewed product quality and brand image as major elements in their fast-fashion brand consumption, which required fast-fashion brands to improve product quality.

More importantly, it might be beneficial for fast-fashion brands to further make efforts to create impressive brand images for consumers, which included corporate images, user's image, service level and consumers' expectation on fast-fashion brands. In addition, shopping experience and product reputation might also be elements that were considered by Chinese consumers and British consumers at different level. Based on the consideration of the specific elements that are generally considered by Chinese consumers and British consumers respectively concerning fast-fashion consumptions, it might provide some insights for fast-fashion brands to develop some effective strategies to improve their competitive edges in the fast-fashion industry and win the loyalty of customers. 


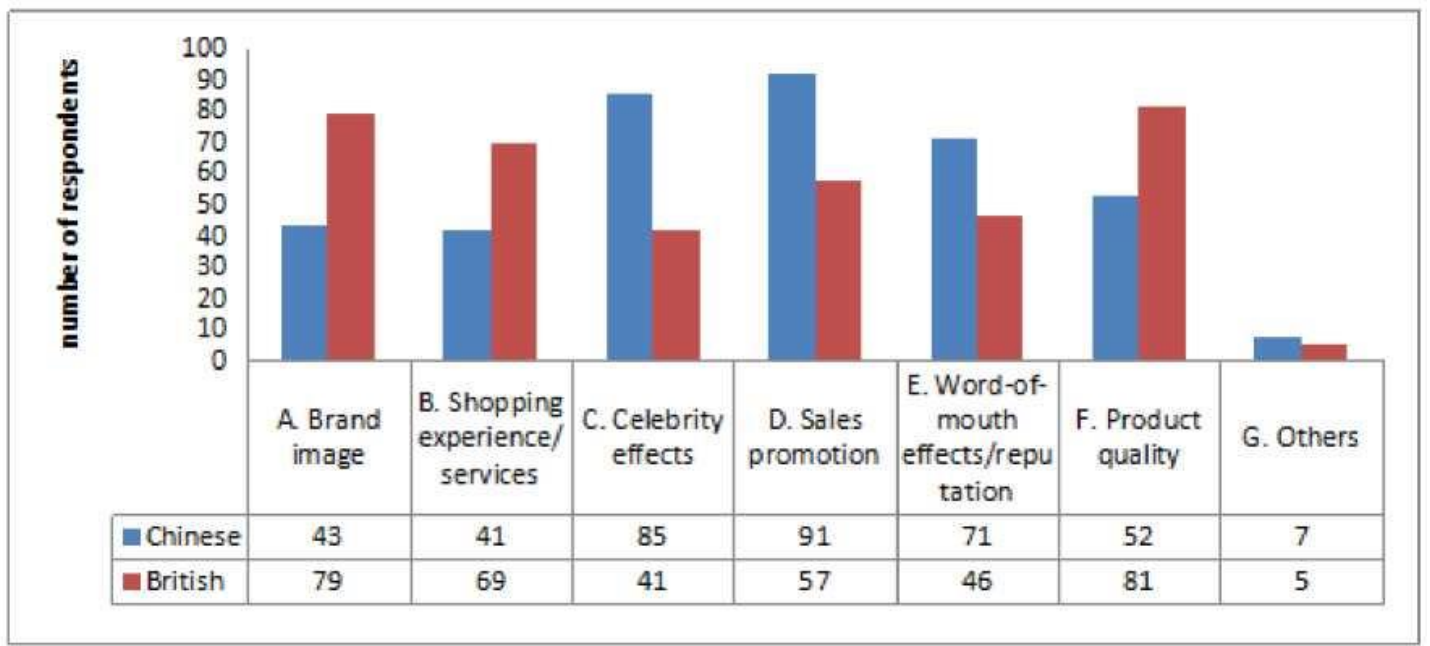

Graph 7. Elements to be considered by Chinese and British consumers in terms of fast-fashion consumption

In the questionnaire section, a question was designed to have a better understanding on popular fast-fashion brands among Chinese consumers and British consumers. It can be observed that 89 respondents of total Chinese consumers preferred Zara and 83 Chinese respondents preferred Giordano, which were two major popular fast-fashion brands among Chinese consumers. In terms of British consumers, Uniqlo and Zara were considered as popular fast-fashion brands, which were selected by 85 British respondents and 77 British respondents respectively. It can be summarized that Chinese consumers and British consumers had favourite fast-fashion brands named Zara in common. What's more, other fast-fashion brands such as Gap and H\&M were also viewed as popular fast-fashion brands by both Chinese consumers and British consumers even though the degree of popularity might be different between these two types of consumers. The following graph can be regarded as a valuable reference for different fast-fashion brands when entering into Chinese market and British market, which was aimed to increase market competitiveness and promote sales growth.

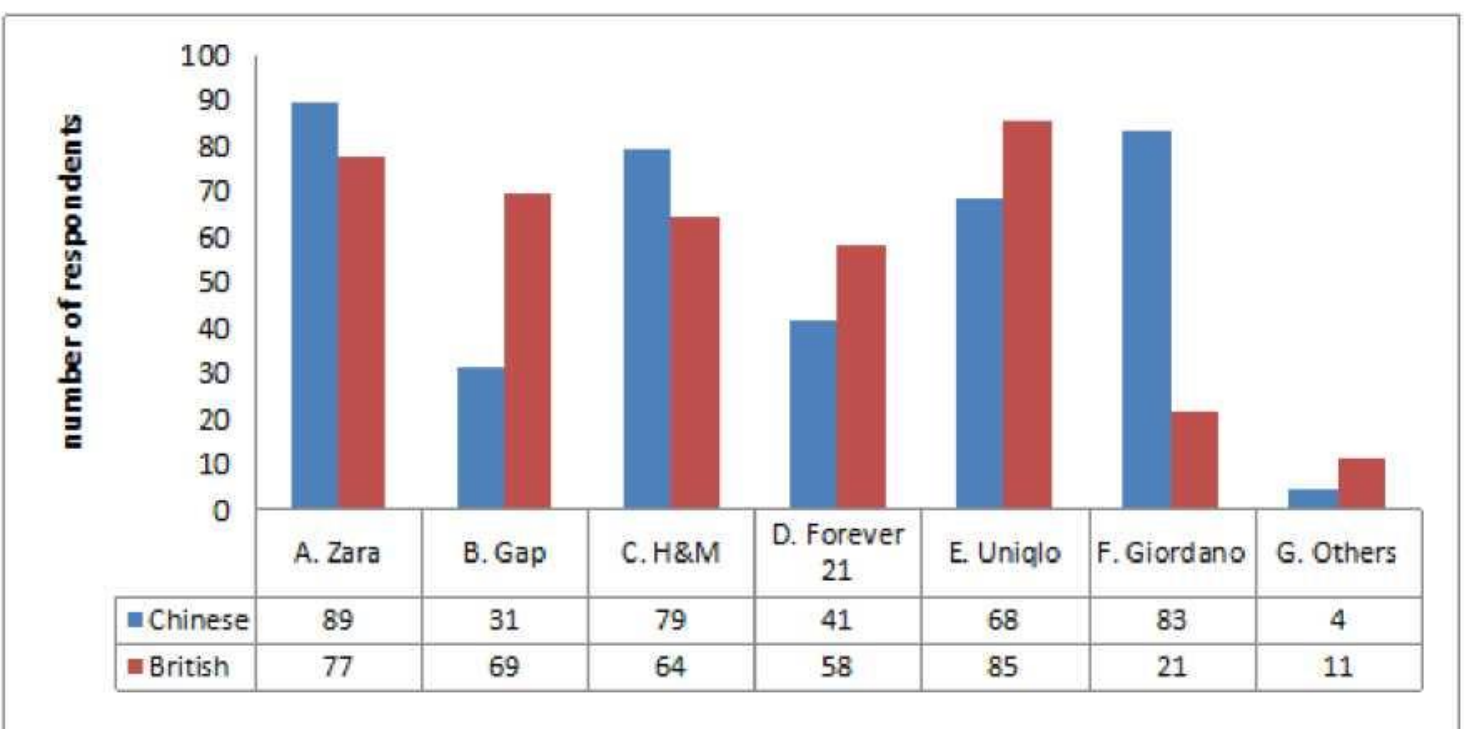

Graph 8. Popular fast-fashion brands among Chinese and British consumer 
From the following graph, it can lead people to have comprehensive knowledge about consumption behaviours of fast-fashion brands for Chinese consumers and British consumers. As for Chinese consumers, as high as 55\% respondents had consumption behaviours of impulse buying, meaning that the majority of Chinese respondents might fail to carry out a comprehensive consideration before making their fast-fashion consumption decisions. These behaviours can be affected by shopping environment and promotional activities. $31 \%$ of Chinese respondents expressed that they had rational consumption behaviours toward fast-fashion goods. While in terms of British respondents, the proportion of British respondents who have rational fast-fashion consumption behaviours accounted for $63 \%$ of the total. Under guideline of the utilitymaximizing rule, most of the British respondents showed that they can make reasonable purchasing decision according to their practical need. The account of impulse buying among British consumers was only $12 \%$. From these figures, it can be seen that compared with Chinese respondents, the British consumers might be relatively more rational when it comes to fast-fashion consumption.

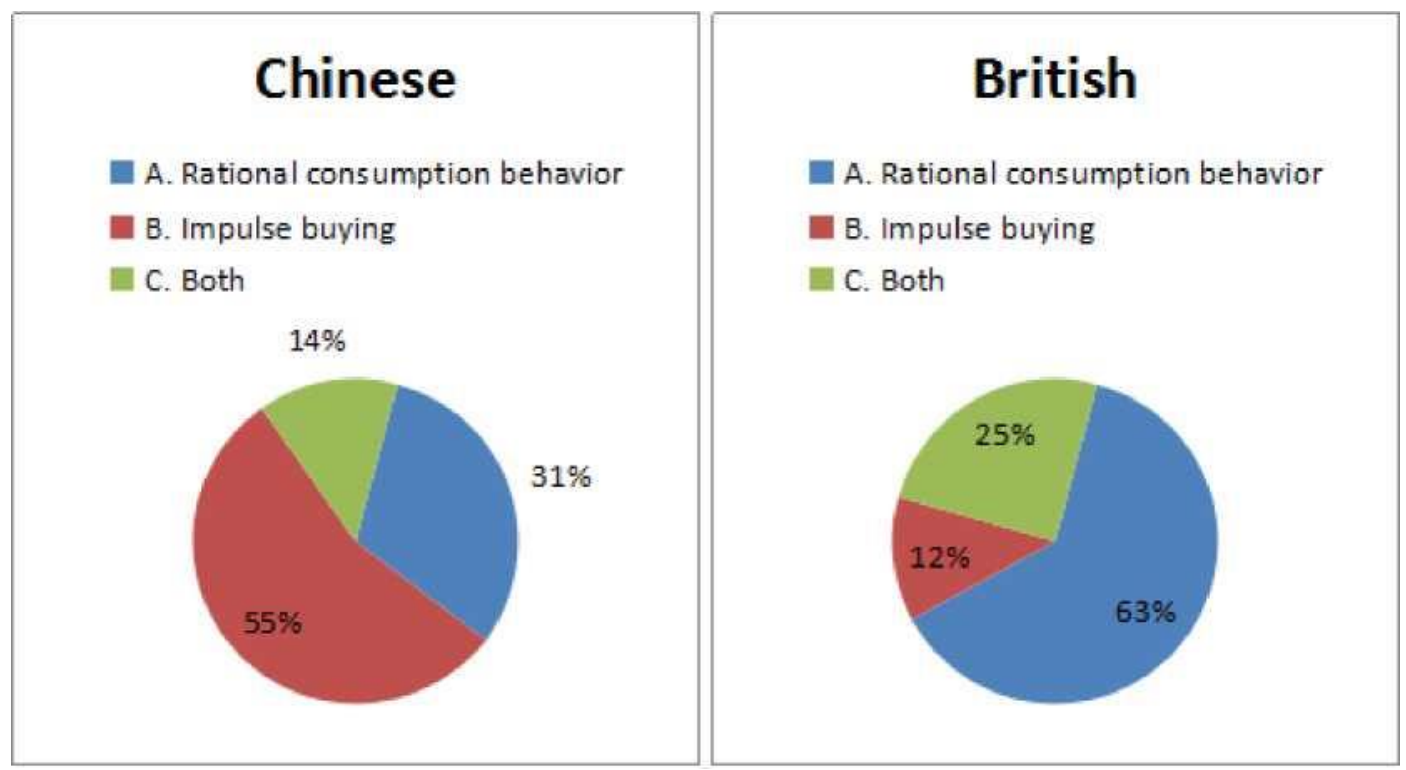

Graph 9. Consumption behaviours of Chinese and British consumers

It is critical for fast-fashion brands to attract potential customers and further turn them into their loyal consumer groups, which is beneficial for fast-fashion brands to save cost in promotion. This question was designed to investigate whether the respondents will be loyal to fast-fashion brands. Consumers with different cultural background from China and Britain held different viewpoints. Neutral attitude from Chinese consumers and British consumers accounted for the largest percentage in two countries. Furthermore, 37 Chinese respondents displayed little disagreement related their loyalty to fast-fashion brands. While 32 British consumers showed that they agreed little to be loyal to fast-fashion brands. 


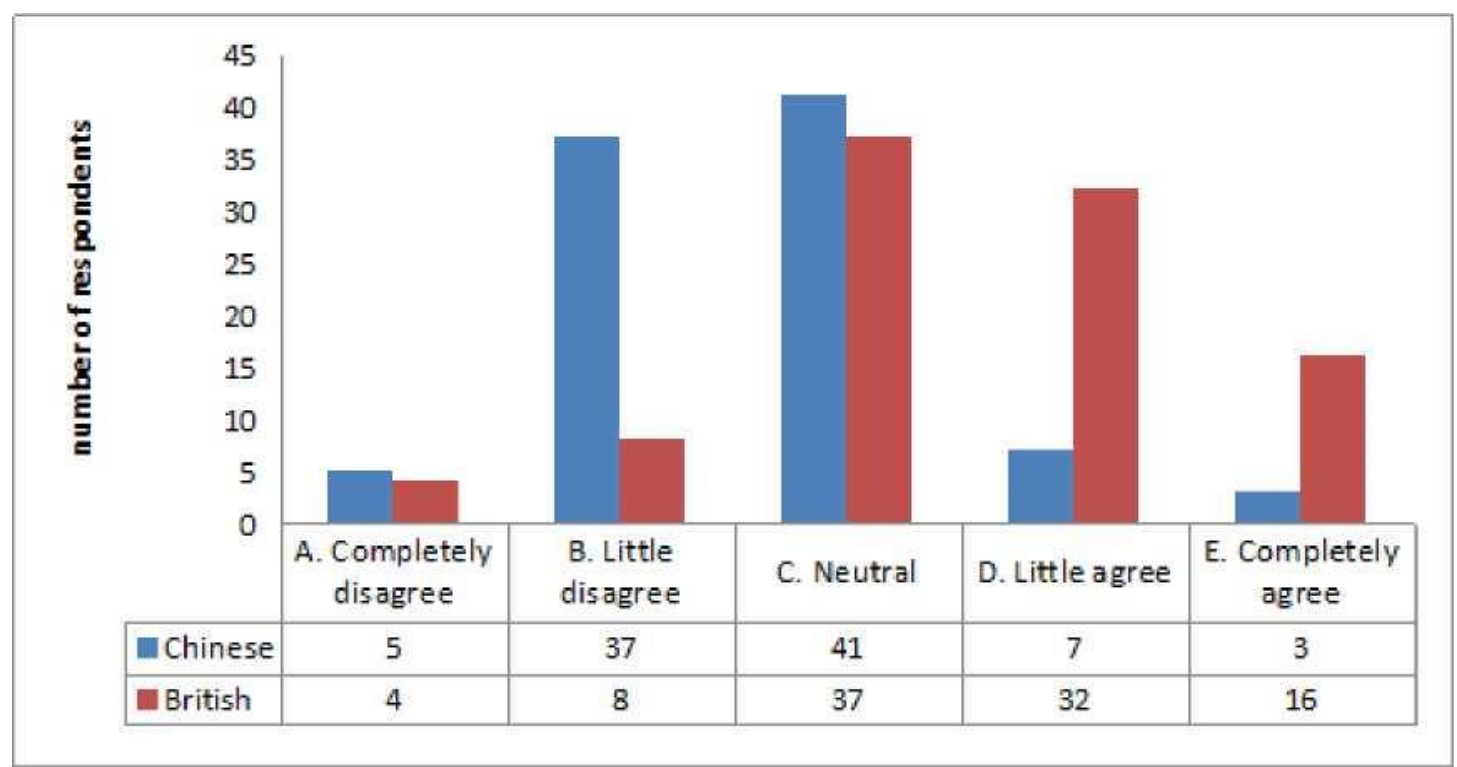

Graph 10. Whether the respondents will be loyal to fast-fashion brands

For the purpose of motivating more consumers' fast-fashion consumption behaviours, it is of great significance to figure out the most effective motivations to attract consumers. Without doubt, it is possible that different consumers might be motivated by different factors and this research made a comparison between Chinese consumers and British consumers in terms of the effective motivation to fast-fashion consumption. Graph 11 was presented to illustrate the findings gained from this research. In terms of Chinese respondents, 88 consumers of total respondents considered sales promotion as the most effective motivations that stimulated them to pursuit fast-fashion consumption. Chinese consumers thought that they could get preferential price from sales promotion. Another motivation was effective marketing initiatives in mind of Chinese consumers. As for British consumers, they considered brand consciousness/brand loyalty and effective marketing initiatives as the most effective motivations to fast-fashion consumption with the support of 81 and 76 respondents respectively. Common motivation to both Chinese and British consumers was effective marketing initiatives, which can be emphasized by fast-fashion brands to put forward strategic marketing measures to enhance brand recognition. Besides, favourable brand image should be taken into consideration by fast-fashion brands in order to better attract and motivate the consumption of British consumers.

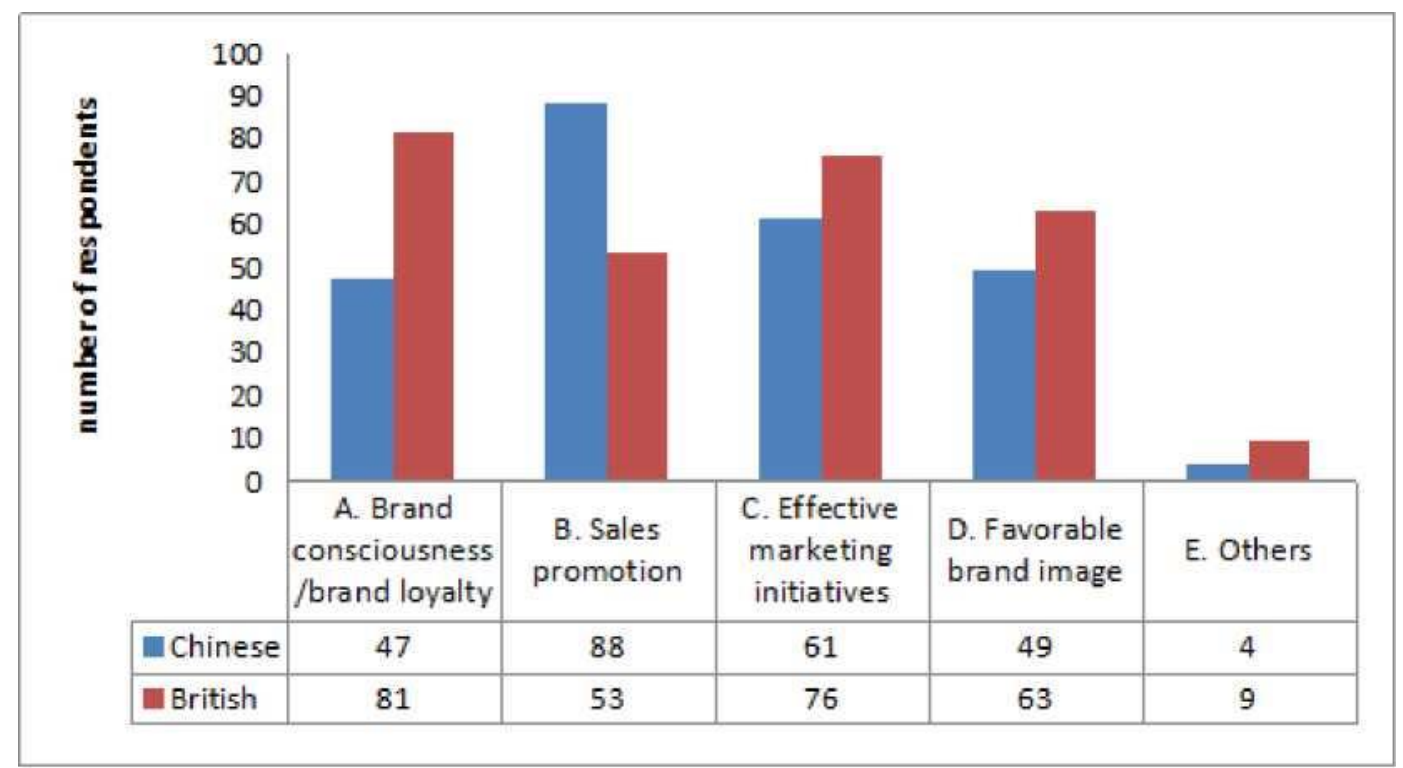

Graph 11. Most effective motivations to fast-fashion consumption (multiple choices) 
Question 12 was designed to explore effective measures that enhance loyalty to fastfashion brands, which gave impetus to fast-fashion brands to get loyal consumer groups. 91 of 93 Chinese respondents took regular sales promotion and 79 of total respondents regarded membership programs as valuable measures to increase their loyalty to fast-fashion brands. While in terms of British respondents, 86 of 97 respondents expressed that enhancing customer interaction was a strategic measure for them to be loyal fast-fashion brands. Effective interaction between fast-fashion brands and customers can help brands to get insightful feedback and solve problems of consumers efficiently. Meanwhile, 77 of 97 respondents viewed regular sales promotion with different forms as strategic measure to enhance loyalty of British consumers. Through sales promotion, consumers can understand unique features of fast-fashion brand that are different from others and make purchasing decisions.

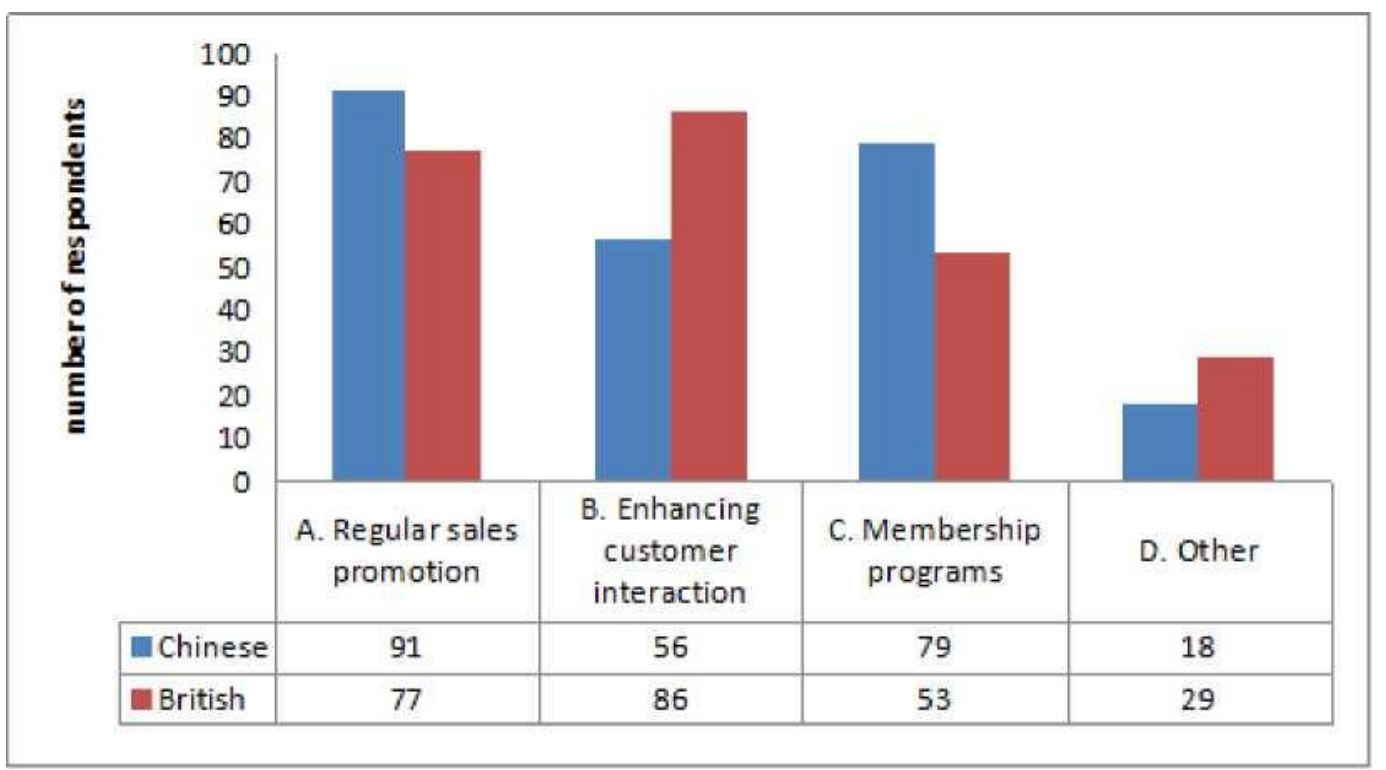

Graph 12. Measures to enhance loyalty to fast-fashion brands (multiple choices)

\section{Conclusions and Recommendations}

\subsection{Conclusion}

In summary, this dissertation was aimed to have an in-depth exploration with regard to consumption behaviors and consumption attitude of fast-fashion brands between Chinese consumers and British consumers. In order to meet research aim and objective, this research was conducted with appropriate research methodology including both qualitative method and quantitative method in order to lead people to have a better understanding on the research results. In particular, questionnaire including a series of relevant questions was well-designed to distribute Chinese consumers and British consumers respectively, which was aimed to find out satisfying answers for research questions.

It can be concluded that there were similarities existing in consumption behavior and attitude between Chinese consumers and British consumers. The demand for fast-fashion brands was presented in the consumption behavior of Chinese consumers and British consumers. Both Chinese consumers and British consumers need purchase fast-fashion brands to meet their hierarchy need in the society. It is widely acknowledged that enhanced hierarchy can facilitate an individual consumer to achieve self-image and self-value. Financial strength of both Chinese consumers and British consumers can exert direct influence on purchasing decision while in department store of fast-fashion brands. Consumers with high income level have strong power in consuming fast-fashion brands like Zara and H\&M while capability of consumers with lower income level is relatively low.

In addition, through this research, it can be gained that both Chinese consumers and British consumers are increasingly aware of brand perception. It is fashionable design, attractive price and other relevant elements that draw attention from Chinese consumers and British consumers and drives them to increase consumption frequencies. Various well-known fast-fashion brands make full use of different channels to collect fashionable information, which endeavors to cater for different needs of different consumers in terms of following fashion trend. Enhanced brand perception allows Chinese consumers and British consumers to have a brand-new 
experience when purchasing fast-fashion brands. What's more, it can be summarized from questionnaire analysis that female consumers accounted for a large proportion among Chinese consumers and British consumers. Among various fast-fashion brands, Zara was a relatively popular brand, which has high reputation from Chinese and British consumers. As for consumers in China and Britain, effective marketing initiatives were considered the most valuable motivations which can stimulate consumers to purchase fast-fashion brands. And viewpoint of Chinese consumers and British consumers is that sales promotion from fast-fashion brands can promote them to be loyal to new fast-fashion brands.

It is no doubt that differences exist in consumption behavior and attitude between Chinese consumers and British consumers. As an emerging market, fast-fashion brand consumption of Chinese consumers is at the stage of growth. Most of the Chinese consumers are full of curiosity about fast-fashion brands and the young people are quite interested in fast-fashion brand consumption. For majority of Chinese consumers, their impulse consumption was more than rational consumption behavior. Without comprehensive consideration before fast-fashion consumption, most of the Chinese consumers are easy to be affected by sales promotion activities and shopping environment in department store of fast-fashion brands. In contrast, as a mature market of fast-fashion brands, Britain has experienced the initial stage of fast-fashion consumption. Therefore, majority of British consumers can adhere to rational attitude in terms of consuming fast-fashion brands.

Within their consumption capability, British consumers are be able to optimize their fast-fashion consumption and make reasonable purchasing decisions which are in accordance their real need. Chinese consumers endow fast-fashion brand consumption with specific implications. They regarded fast-fashion consumption as a way to show off their financial capability, social status and individual power. In the mind of Chinese consumers, fast-fashion brand consumption can make them distinguish from others. Carrying well-known fast-fashion brands with a limited number can get admiration and respect from the public, which caters for their need of personal status. However, it can be learned that British consumers are more willing to focus on inner quality of fastfashion brands. They preferred fast-fashion brands with superior and reliable quality, which was primary element considered by British consumers in fast-fashion consumption. Fast-fashion brand consumption is a regular behavior for British consumers rather than psychology of showing off.

From this research, it can have a holistic understanding on influential factors such as social factors and psychological factors of consumption behavior and attitude between Chinese consumers and British consumers. Therefore, this research concluded effective strategic measures to stimulate Chinese consumers and British consumers to purchase fast-fashion brands, which were of great benefit for various fast-fashion brands to attract attention from Chinese consumers and British consumers respectively. As international fast-fashion brands like Zara and H\&M, they should enhance brand consciousness and have specific brand positioning. In view of the increasing fierce market competition, fast-fashion brands should create their products with unique features, which is beneficial to attract potential customers and further turn them into loyal customers. Unique designing element and rapid updating speed of fast-fashion products are all available to keep loyal consumers. In collecting insightful information, designers and managers of department stores should enhance interaction with consumers to understand their idea about fast-fashion brands and further make final design satisfy requirement of consumers. Meanwhile, market positioning strategy should be paid great attention. Setting up effective marketing initiatives is essential for fast-fashion brands in integrating market resources. In addition to updating speed, supplying efficiency is also critical so that effective supply chain should be built to promote fast-fashion consumption.

\subsection{Implications for Marketing}

Based on the above comparative analysis of Chinese consumers and British consumers' attitude toward fast-fashion brands, it might be beneficial for fast-fashion brands to adopt different marketing strategies to cater to different types of consumers. And the following aspects might be taken into consideration.

\section{For Chinese Consumers:}

$\checkmark$ Celebrity effects. Chinese consumers are inclined to purchase products whose spokesman is celebrity. Therefore, it is essential for fast-fashion brands to utilize celebrity effects to motivate Chinese consumers. Inviting popular celebrity to make advertisement for fast-fashion brands and employing celebrity to attend charity events regarding to fast-fashion brands are effective to stimulate brand awareness of Chinese consumers and get their attention, which facilitates consumption preference of Chinese consumers.

$\checkmark$ Sales promotion. Sales promotion is a valuable method for fast-fashion brands to increase sales volume and enhance performance. It is necessary for fast-fashion brands to choose appropriate means of sales promotion in accordance with Chinese market situation and consumption preference of Chinese consumers. With pertinence and timeliness, sales promotion can encourage Chinese consumers to accept new fast-fashion 
brands and win loyal consumers.

$\checkmark$ Enhance interaction with customers through social media platforms like Wechat. With dependence on smart phone, fast-fashion brands find it more efficient and convenient for them to understand demand of Chinese consumers and solve their problems and confusing. With features of time effective and cost effective, social media can make use of advanced tool such as Trackur to track relevant information related to fast-fashion brands and further analyze the results.

For British Consumers:

$\checkmark$ Continue to emphasize on quality and comfort. Different from Chinese consumers, British consumers are inclined to have more emphasis on quality and comfort while consuming fast-fashion brands. Choice of good fabrics and fine workmanship should be ensured to improve quality and comfort of fast-fashion brands and satisfy inner pursuit of British consumers.

$\checkmark$ Emphasis on fashion design and fashion elements through effective marketing and advertising. As a matured market, British consumers have experienced consumption of fast-fashion brands. Therefore, it requires fast-fashion brands to devote more energy when shaping brand and designing products, which is helpful to attract more British consumers. What's more, it should draw support effective marketing and advertising to convey useful information to British consumers and get their attention. Moreover, rapid updating speed of fast-fashion brands should be guaranteed according to popular fashion trend.

$\checkmark$ Focus on showing personality and individual styles. As British consumers, they are more likely to display personality different from others. They are willing to purchase fast-fashion brands which can represent their individual styles. Therefore, fast-fashion brands can produce the limited amount of clothing. Meanwhile, offering a wide variety of products for British consumers to choose is a strategic way to cater for the need of British consumers in seeking individual styles.

\subsection{Research Limitations}

This research only distributed questionnaires to 100 Chinese consumers and 100 British consumers respectively, which might not be large enough to conduct a convincing research. If more time is allowed, more questionnaires will be distributed to Chinese consumers and British consumers to get effective feedback.

Interviews with managers of fast-fashion brands might have been conducted if more time is given. As a reliable research method, having interview is regarded as a direct way to collect trustworthy information from department store managers of fast-fashion brands to gain more inspiring data to support the exploration of this research.

\section{Acknowledgement}

Here after the completion of my dissertation, I'd like to express my most sincere appreciation for all those who kindly help and support me in this process. When reflecting on the writing process of this dissertation, it seems like a challenging but fruitful journey, in which I confronted with various new and challenging items and also gained some memorable things.

I feel grateful for the opportunity to be guided by supervisor who offered a lot of inspiring advices for helping me develop a logic and convincing academic research. Without the guidance and help of my supervisor, I might fail to complete my dissertation in a timely and satisfactory manner.

Meanwhile, I think it's lucky to have the support of my friends. We shared this learning journey together to seek effective ways to carry out a well-designed and considerate academic research and find solutions to the difficulties and challenges we met in the writing process.

In addition, I think the strong support of my parents, who show me unconditional love and care in my whole learning journey.

Thank you for all their help and support and I will do my best to become a better person.

\section{References}

Bakewell, C., Mitchell, V. W., \& Rothwell, M. (2006). UK Generation Y male fashion consciousness. Journal of Fashion Marketing and Management: An International Journal, 10(2), 169-180.

Barnes, L., \& Lea-Greenwood, G. (2006). Fast fashioning the supply chain: shaping the research agenda. Journal of Fashion Marketing and Management: An International Journal, 10(3), 259-271.

Barnes, L., \& Lea-Greenwood, G. (2010). Fast fashion in the retail store environment. International Journal of 
Retail \& Distribution Management, 38(10), 760-772.

Belk, R. W., Devinney, T., \& Eckhardt, G. (2005).Consumer ethics across cultures. Consumption Markets \& Culture, 8(3), 275-289.

Bhardwaj, V., \& Fairhurst, A. (2010). Fast fashion: response to changes in the fashion industry. The International Review of Retail, Distribution and Consumer Research, 20(1), 165-173.

Bruce, M., \& Daly, L. (2006). Buyer behaviour for fast fashion. Journal of Fashion Marketing and Management: An International Journal, 10(3), 329-344.

Burck, C. (2005). Comparing qualitative research methodologies for systemic research: The use of grounded theory, discourse analysis and narrative analysis. Journal of Family Therapy, 27(3), 237-262.

Choi, T. M., Liu, N., Liu, S. C., Mak, J., \& To, Y. T. (2010). Fast fashion brand extensions: An empirical study of consumer preferences. The Journal of Brand Management, 17(7), 472-487.

Creswell, J. W. (2013). Research design: Qualitative, quantitative, and mixed methods approaches. Sage Publications.

Fuchs, C., \& Diamantopoulos, A. (2010). Evaluating the effectiveness of brandpositioning strategies from a consumer perspective. European Journal of Marketing, 44(11/12), 1763-1786.

Gabrielli, V., Baghi, I., \& Codeluppi, V. (2013). Consumption practices of fast fashion products: a consumer-based approach. Journal of Fashion Marketing and Management: An International Journal, 17(2), 206-224.

Goh, K. Y., Heng, C. S., \& Lin, Z. (2013). Social media brand community and consumer behavior: Quantifying the relative impact of user-and marketer-generated content. Information Systems Research, 24(1), 88-107.

Goldsmith, R. E., \& Clark, R. A. (2008). An analysis of factors affecting fashion opinion leadership and fashion opinion seeking. Journal of Fashion Marketing and Management: An International Journal, 12(3), 308-322.

Goldsmith, R. E., Flynn, L. R., \& Kim, D. (2010).Status consumption and price sensitivity. Journal of Marketing Theory and Practice, 18(4), 323-338.

Howarton, R., \& Lee, B. (2010). Market analysis of fit preferences of female boomers. Journal of Fashion Marketing and Management: An International Journal, 14(2), 219-229.

Hustvedt, G., \& Dickson, M. A. (2009). Consumer likelihood of purchasing organic cotton apparel: Influence of attitudes and self-identity. Journal of Fashion Marketing and Management: An International Journal, 13(1), 49-65.

Johar, G. V., Sengupta, J., \& Aaker, J. L. (2005). Two roads to updating brand personality impressions: Trait versus evaluative inferencing. Journal of Marketing Research, 42(4), 458-469.

Joo Park, E., Young Kim, E., \& Cardona Forney, J. (2006). A structural model of fashion-oriented impulse buying behavior. Journal of Fashion Marketing and Management: An International Journal, 10(4), 433-446.

Joy, A., Sherry Jr, J. F., Venkatesh, A., Wang, J., \& Chan, R. (2012). Fast fashion, sustainability, and the ethical appeal of luxury brands. Fashion Theory, 16(3), 273-295.

Knight, D. K., \& Young Kim, E. (2007). Japanese consumers' need for uniqueness: Effects on brand perceptions and purchase intention. Journal of Fashion Marketing and Management: An International Journal, 11(2), 270-280.

Lopez, C., \& Fan, Y. (2009). Internationalisation of the Spanish fashion brand Zara. Journal of Fashion Marketing and Management: An International Journal, 13(2), 279-296.

Maxwell, J. A. (2012). Qualitative research design: An interactive approach: An interactive approach. Sage.

Peffers, K., Tuunanen, T., Rothenberger, M. A., \& Chatterjee, S. (2007). A design science research methodology for information systems research. Journal of management information systems, 24(3), 45-77.

Poston, B. (2009). Maslow's hierarchy of needs. Surgical Technologist, 348.

Rageh Ismail, A., \& Spinelli, G. (2012). Effects of brand love, personality and image on word of mouth: The case of fashion brands among young consumers. Journal of Fashion Marketing and Management: An International Journal, 16(4), 386-398.

Rocha, M. A. V., Hammond, L., \& Hawkins, D. (2005). Age, gender and national factors in fashion consumption. Journal of Fashion Marketing and Management: An International Journal, 9(4), 380-390. 
Sheridan, M., Moore, C., \& Nobbs, K. (2006). Fast fashion requires fast marketing: The role of category management in fast fashion positioning. Journal of Fashion Marketing and Management: An International Journal, 10(3), 301-315.

Terziovski, M. (2010). Innovation practice and its performance implications in small and medium enterprises (SMEs) in the manufacturing sector: a resource - based view. Strategic Management Journal, 31(8), 892-902.

Tokatli, N. (2008). Global sourcing: insights from the global clothing industry — the case of Zara, a fast fashion retailer. Journal of Economic Geography, 8(1), 21-38.

Turker, D., \& Altuntas, C. (2014). Sustainable supply chain management in the fast fashion industry: An analysis of corporate reports. European Management Journal, 32(5), 837-849.

Turner III, D. W. (2010). Qualitative interview design: A practical guide for novice investigators. The Qualitative Report, 15(3), 754.

Tyler, D., Heeley, J., \& Bhamra, T. (2006). Supply chain influences on new product development in fashion clothing. Journal of Fashion Marketing and Management: An International Journal, 10(3), 316-328.

White, K., \& Dahl, D. W. (2006). To be or not be? The influence of dissociative reference groups on consumer preferences. Journal of Consumer Psychology, 16(4), 404-414.

Zhang, B., \& Kim, J. H. (2013). Luxury fashion consumption in China: Factors affecting attitude and purchase intent. Journal of Retailing and Consumer Services, 20(1), 68-79.

Appendix 1. Questionnaire

1. Please choose your gender:
A. Female
B. Male

2. Please choose your age:
A. Below 20
B. Between 20 and 29
C. Between 30 and 39
D. Between 40 and 49
E. Between 50 and 59
F. 60 or above

3. Please choose your income level:
A. Below $£ 10,000$
B. Between $£ 10,000$ and $£ 20,000$
C. Between $£ 20,000$ and $£ 40,000$
D. Above $£ 40,000$

4. Please share your frequencies of fast-fashion consumption:
A. Less than 2 times per month
B. Between 2 and 5 times per months
C. Between 6 and 10 times per months
D. Above 10 times 
5. How many years have you been engaged in fast-fashion consumption?
A. Less than 1 year
B. Between 1 and 3 years
C. Between 4 and 5 years
D. Above 5 years

6. What are your reasons for fast-fashion consumption? (multiple choices)
A. Fashion design
B. Superior quality
C. Attractive Price
D. Personal style
E. Convenience
F. Follow the trends
G. Others

7. What elements will you consider in terms of fast-fashion consumption? (multiple choices)
A. Brand image
B. Shopping experience/services
C. Celebrity effects
D. Sales promotion
E. Word-of-mouth effects/reputation
F. Product quality
G. Others:

8. Which of the following fast-brands are your favorites? (multiple choices)
A. Zara
B. Gap
C. $\mathrm{H} \& \mathrm{M}$
D. Forever 21
E. Uniqlo
F. Giordano
G. Others:

9. In terms of your fast-fashion consumption, it is generally:
A. Rational consumption behaviour
B. Impulse buying
C. Both

10. To what extent do you think you will be loyal to fast-fashion brands?
A. Completely disagree
B. Little disagree
C. Neutral 
D. Little agree

E. Completely agree

11: What are the most effective motivations to your fast-fashion consumption? (multiple choices)
A. Brand consciousness/brand loyalty
B. Sales promotion
C. Effective marketing initiatives
D. Favorable brand image
E. Others:

12. What measures can be used to enhance your loyalty to fast-fashion brands?
A. Regular sales promotion
B. Enhancing customer interaction
C. Membership programs
Other:

\section{Copyrights}

Copyright for this article is retained by the author(s), with first publication rights granted to the journal.

This is an open-access article distributed under the terms and conditions of the Creative Commons Attribution license (http://creativecommons.org/licenses/by/4.0/). 